\title{
Abrin Induces HeLa Cell Apoptosis by Cytochrome $c$ Release and Caspase Activation
}

\author{
Xiaoling $\mathbf{Q u}^{\dagger}$ and Liuting Qing** \\ Institute of Virology, College of Life Sciences, Wuhan University, Wuhan 430072, P. R. China \\ College of Animal Sciences, Huazhong Agricultural University, Wuhan 430070, P. R..China
}

Received 15 July 2003, Accepted 7 November 2003

\begin{abstract}
We identified apoptosis as being a significant mechanism of toxicity following the exposure of HeLa cell cultures to abrin holotoxin, which is in addition to its inhibition of protein biosynthesis by $\mathrm{N}$-glycosidase activity. The treatment of HeLa cell cultures with abrin resulted in apoptotic cell death, as characterized by morphological and biochemical changes, i.e., cell shrinkage, internucleosomal DNA fragmentation, the occurrence of hypodiploid DNA, chromatin condensation, nuclear breakdown, DNA single strand breaks by TUNEL assay, and phosphatidylserine (PS) externalization. This apoptotic cell death was accompanied by caspase-9 and caspase- 3 activation, as indicated by the cleavage of caspase substrates, which was preceded by mitochondrial cytochrome $c$ release. The broad-spectrum caspase inhibitor, benzyloxycarbonyl-Val-Ala-Asp-fluoromethyl ketone (zVADfmk), prevented abrin-triggered caspase activation and partially abolished apoptotic cell death, but did not affect mitochondrial cytochrome $c$ release. These results suggest that the release of mitochondrial cytochrome $c$, and the sequential caspase-9 and caspase- 3 activations are important events in the signal transduction pathway of abrin-induced apoptotic cell death in the HeLa cell line.
\end{abstract}

Keywords: Abrin, Apoptosis, Caspase-3, Caspase-9, Cytochrome $c$ release

\footnotetext{
Abbreviation: RIPs, ribosome-inactivating protein(s); PARP, poly(ADP-ribose) polymerase; zVAD-fmk, benzyloxycarbonyl-ValAla-Asp-fluoromethyl ketone; PI, propidium imidone; TdT, terminal deoxynucleotidyl transferase; TUNEL, terminal deoxynucleotidyl transferase (TdT)-catalyzed dUTP-nick end labeling; Ac-DEVDAMC, acetyl-Asp-Glu-Val-Asp-7-amido-4-methylcoumarin; Ac-LEHDAMC, acetyl-Leu-Glu-His-Asp-amino-4-methylcoumarin; PBS, phosphate-buffered saline; PS, phosphatidylserine; SDS-PAGE, sodium dodecyl sulfate-polyacrylamide gel electrophoresis.
}

*To whom correspondence should be addressed.

Tel: 0086-027-87282608; 0086-13971360120

E-mail: qingliuting@yahoo.com.cn

\section{Introduction}

Ribosome-inactivating protein(s) (RIPs) are a group of plant enzymes that can inhibit polypeptide-chain elongation by inactivating ribosomes (Liu et al., 2000). The molecular mechanism of such inhibition involves specific $\mathrm{N}$-glycosidase activity that hydrolytically cleaves the N-glycosidic bond of adenine at position 4324 of $28 \mathrm{~S}$ rRNA (Endo et al., 1987). The RIPs are divided into two groups: (i) single-chain glycoproteins type-I RIPs, and (ii) heterodimer protein type-II RIPs. Abrin, a lectin that was isolated from the seeds of the plant Abrus precatorius, belongs to the type-II RIPs, which consist of a toxophoric A-chain with protein synthesis inhibitory activity and a lectin B-chain that binds to Dgalactose moieties on the cell membrane. The A-chain is transferred across the plasma membrane by the B-chain via endocytotic vesicles into the cytoplasma of cells, and then irreversibly inactivate ribosomes, thus inhibiting protein synthesis and resulting in eventual cell death (Wu et al., 1998). In addition to their abilities to inhibit protein biosynthesis, recent studies have demonstrated that ricin, diphtheric toxin, and other familiar toxins induce cell lysis and DNA fragmentation in a process reminiscent of programmed cell death or apoptosis (Hughes et al., 1996; Komatsu et al., 1998). Although the mechanism of cell lysis or apoptosis by these toxins remains unclear, it has been reported that the inhibition of protein synthesis and the induction of apoptosis may be mediated by different segments of the ricin A-chain molecule (Baluna et al., 1999). Therefore, it is an attractive hypothesis that abrin adopts alternative molecular mechanism to exert cytotoxicity in addition to its inhibitory effect on protein synthesis.

Apoptosis, a major form of cell death, is characterized by a series of stereotypic morphological and biochemical features, such as a loss of cell volume, membrane blebbing, chromatin clumping, nuclear collapse, and internucleosomal DNA cleavage (DNA fragmentation). The process is essential for development, the maintenance of tissue homeostasis, and the 
elimination of excess or harmful cells in metazoan organisms (Jacobson et al., 1997). Various stimuli, including cytokines, anticancer drugs, growth factor deprivation, radiation damage and so on can cause a cell to undergo apoptotic cell death (Green, 1998). In the past decade, the translocation of cytochrome $c$ from the mitochondrial intermembrane to the cytosol and the subsequent activation of caspases have been identified to be the major steps in the apoptotic process. After the induction of apoptosis by many different stimuli, holocytochrome $c$, which normally resides exclusively in the intermembrane space of mitochondria, is released into the cytosol following the opening of the mitochondrial permeability transition pore (Reed, 1997). In the presence of dATP/ATP and cytochrome $c$, the long N-terminal domain of procaspase-9 interacts with Apaf-1 resulting in the activation of caspase-9 $(\mathrm{Li}$ et al., 1997), which in turn cleaves and activates effector caspases such as caspase-3, -6, -7, etc. (Muzio et al., 1997). These effector caspases, which are responsible for many of the biochemical and morphological changes associated with apoptosis, then cleave intracellular substrates like poly(ADPribose) polymerase (PARP) and lamins during the execution phase of apoptosis (Cryns et al., 1998).

The elucidation of the molecular mechanism and the signal transduction mechanism of abrin-induced cell death is important for the future development of potential proteinaceous cancer chemotherapeutic agents. In the present work, we evaluated the induction of apoptosis by abrin in HeLa cells. The toxin triggered typical apoptotic cell death in a dose- and time-dependent manner, and during this apoptotic process cytochrome $c$ release from mitochondria to the cytosol was observed at an early stage. The sequential activations of caspase- 9 and caspase- 3 were also investigated. Taken together, cytochrome $c$ release and caspase activation might be involved in a common pathway of apoptotic cell death induced by the toxin abrin.

\section{Materials and Methods}

Materials Abrin was isolated from the seeds of Abrus precatorius, as described by Wu et al. (2001). The broad-spectrum caspase inhibitor benzyloxycarbonyl-Val-Ala-Asp-fluoromethyl ketone (zVAD-fmk), Hoechst 33342, propidium imidone (PI) and Triton X-100 were purchased from Sigma. The terminal deoxynucleotidyl transferase (TdT)-catalyzed dUTP-nick end labeling (TUNEL) In Situ Cell Death Detection Kit and the AnnexinV-FLUOS/PI Staining Kit were the products of Roche Molecular Biochemicals (Basel, Switzerland). The CaspASE ${ }^{\mathrm{TM}}$ assay system containing the fluorescent tetrapeptide protease substrates, acetyl-Asp-Glu-Val-Asp-7-amino-4-methylcoumarin (Ac-DEVD-AMC) or acetyl-Leu-Glu-His-Asp-7-amino-4methylcoumarin (Ac-LEHD-AMC), was purchased from GIBCO/ BRL (Grand island, USA). RNase A and proteinase $\mathrm{K}$ were purchased from Promega (Madison, USA). Antibodies against cytochrome $c$ (clone 7H8.2C12), PARP (clone C2-10) and cytochrome oxidase subunit were purchased from Pharmingen (San
Diego, USA). The anti-actin antibodies (clone C4) were kindly provided by Dr. Masazumi Sameshima (The Tokyo Metropolitan Institute of Medical Science, Japan). All other chemicals were of analytical grade.

Cell culture HeLa cells were maintained in Roswell Park Memorial Institute (RPMI) 1640 medium (GIBCO/BRL) supplemented with $4 \mathrm{mM}$ L-glutamine, $100 \mathrm{U} / \mathrm{ml}$ penicillin, $100 \mu \mathrm{g} /$ $\mathrm{ml}$ streptomycin, and $10 \%$ heat-inactivated $\left(30 \mathrm{~min}, 56^{\circ} \mathrm{C}\right)$ fetal calf serum at $37^{\circ} \mathrm{C}$ in a humidified $5 \% \mathrm{CO}_{2}$ atmosphere. The cells were routinely passaged every 2-3 d and seeded in 24-well plates or chamber slides $24 \mathrm{~h}$ prior to abrin application. For inhibition experiments, the cells were preincubated with zVAD-fmk for $30 \mathrm{~min}$ at $37^{\circ} \mathrm{C}$, if not indicated otherwise.

Assessment of apoptosis HeLa cells $\left(5 \times 10^{6}\right.$ cells $\left./ \mathrm{ml}\right)$ in RPMI 1640 medium were incubated with the indicated concentrations of abrin in the presence or absence of caspase inhibitor at $37^{\circ} \mathrm{C}$ for indicated time periods $(2,8,15,24$, or $36 \mathrm{~h})$. Apoptotic cell death was evaluated using the following series of methods.

DNA fragmentation analysis Cells $\left(2 \times 10^{5}\right.$ per sample $)$ were harvested, washed with phosphate-buffered saline (PBS), lysed for $1 \mathrm{~h}$ at $50^{\circ} \mathrm{C}$ in lysis buffer $(0.1 \%$ Triton X-100, $50 \mathrm{mM}$ Tris- $\mathrm{HCl}, \mathrm{pH}$ 8.0, $5 \mathrm{mM}$ EDTA-Na, $150 \mathrm{mM} \mathrm{NaCl}$ ) supplemented with proteinase $\mathrm{K}(5 \mathrm{mg} / \mathrm{ml})$ and digested for $1 \mathrm{~h}$ with RNase A $(0.5 \mathrm{mg} / \mathrm{ml})$. After two extractions with phenol and one extraction with phenol/ chloroform/isoamylacohol $(25: 24: 1)$, the DNA was precipitated with 0.1 volumes of $5 \mathrm{M}$ ammonium acetate and 2 volumes of absolute ethanol at $-20^{\circ} \mathrm{C}$ overnight, and then washed with ice-cold $70 \%$ ethanol, air-dried, and resolved in $50 \mu \mathrm{l} \mathrm{TE}$ buffer (10 mM Tris, $1 \mathrm{mM}$ EDTA-Na $2, \mathrm{pH} 8.0$ ). Ten $\mu \mathrm{g}$ of DNA was separated in a $1.5 \%$ agarose gel and visualized by ethidium bromide staining under ultraviolet light.

Flow cytometry analysis of hypodiploid nuclei The reduced DNA contents of apoptotic nuclei appeared as a broad hypodiploid DNA peak in the red fluorescence channels after PI staining. Analysis of hypodiploid DNA by flow cytometry was performed as follows. Briefly, cells samples $\left(2 \times 10^{5}\right)$ resuspended in $300 \mu \mathrm{l}$ PBS were fixed by adding $750 \mu \mathrm{l}$ of ice-cold $70 \%$ ethanol and incubated at $4^{\circ} \mathrm{C}$ for $12 \mathrm{~h}$. After washing with PBS, the cell pellet was gently resuspended in $300 \mu \mathrm{l}$ hypotonic fluorochrome PI solution $(50 \mu \mathrm{g} / \mathrm{ml}$ PI in $0.1 \%$ sodium citrate plus $0.1 \%$ Triton X-100) containing $0.5 \mathrm{mg} / \mathrm{ml}$ RNase $\mathrm{A}$, and then incubated at $4^{\circ} \mathrm{C}$ in the dark for $20 \mathrm{~min}$. After another two washes with PBS, the DNA content of each sample was measured by flow cytometry (FACScan, Becton Dickinson, Lincoln Park, USA) by plotting PI fluorescence intensity as a histogram plot. The percentage of apoptotic nuclei (subdiploid peak in the DNA fluorescence histogram) was calculated using the Consort 30 program (Becton Dickinson).

Hoechst 33342 staining Cells seeded in chamber slides were treated with abrin as described above. At the indicated times the medium was removed, and the cells were washed twice with PBS, fixed in 3\% paraformaldehyde for $20 \mathrm{~min}$, then rewashed, and stained with Hoechst $33342(10 \mu \mathrm{g} / \mathrm{ml})$ at $37^{\circ} \mathrm{C}$ for $20 \mathrm{~min}$ in the dark. After 2-3 washes with PBS, the slides were covered with coverslips and 
viewed under a fluorescence microscope (Olympus, New York, USA) at $450-490 \mathrm{~nm}$.

TUNEL assay Apoptosis was detected by TUNEL assay using an In Situ Cell Death Detection Kit, according to the manufacturer's recommendations. Briefly, after the cells washed, samples were fixed with $4 \%$ paraformaldehyde and permeabilized in permeabilization solution $(0.1 \%$ Triton $\mathrm{X}-100,0.1 \%$ sodium citrate), the rewashed cells were incubated in a humidified chamber for $1 \mathrm{~h}$ at $37^{\circ} \mathrm{C}$ with a reaction mixture containing $\mathrm{TdT}$ and fluorescein isothiocyanateconjugated-11-dUTP to label the exposed 3'-hydroxyl ends of nicked single strand DNA. The samples were analyzed under a fluorescence microscope (Olympus) using an excitation wavelength in the range $450-500 \mathrm{~nm}$ (e.g. $488 \mathrm{~nm})$.

Annexin V-FLUOS/PI assessment Annexin V-FLUOS in combination with PI staining was used to determine phosphatidylserine (PS) exposure in apoptotic cells, by using an Annexin V-FLUOS/PI Staining Kit. In brief, cells were washed twice with ice-cold PBS, resuspended in binding buffer (10 mM Hepes$\mathrm{NaOH}, \mathrm{pH} 7.4,140 \mathrm{mM} \mathrm{NaCl}, 2.5 \mathrm{mM} \mathrm{CaCl}_{2}$ ), and incubated for 25 min in the dark at room temperature with fluorescein-conjugated Annexin V $(1 \mu \mathrm{g} / \mathrm{ml})$ and $5 \mu \mathrm{g} / \mathrm{ml}$ PI. Cells were observed under a fluorescence microscope (Olympus) at 450-500 nm (e.g. $488 \mathrm{~nm}$ ).

Preparation of subcellular fractions and immunoblotting Cells were harvested by centrifugation at $600 \times g$ for $10 \mathrm{~min}$ at $4^{\circ} \mathrm{C}$. The cell pellets obtained were washed once with ice-cold PBS and resuspended in five volumes of buffer A ( $20 \mathrm{mM}$ Hepes- $\mathrm{KOH}$, $\mathrm{pH}$ 7.5, $10 \mathrm{mM} \mathrm{KCl}, 1.5 \mathrm{mM} \mathrm{MgCl}, 1 \mathrm{mM}$ EDTA- $\mathrm{Na}_{2}, 1 \mathrm{mM}$ EGTA$\mathrm{Na}_{2}, 1 \mathrm{mM}$ dithiothreitol, and $0.1 \mathrm{mM}$ phenylmethylsulfonyl fluoride) containing $250 \mathrm{mM}$ sucrose. The cells were then homogenized with 40 strokes of a Dounce homogenizer, and the homogenates were centrifuged twice at $750 \times g$ for $10 \mathrm{~min}$ at $4^{\circ} \mathrm{C}$ to remove nuclei and unbroken cells. Supernatants were centrifuged at $10,000 \times g$ for $15 \mathrm{~min}$ at $4^{\circ} \mathrm{C}$, and the resulting mitochondria pellets were resuspended in buffer A containing $250 \mathrm{mM}$ sucrose and frozen as multiple samples at $-80^{\circ} \mathrm{C}$. The supernatants of the above $10,000 \times g$ spin, referred to as the cytosolic fraction, were divided into samples and frozen at $-80^{\circ} \mathrm{C}$ for further experiments. The protein content of each extract was determined by Bradford assay (Bio-Rad, Hercules, USA). Protein samples $(25 \mu \mathrm{g})$ were boiled in Laemmli buffer (Bio-Rad) for $5 \mathrm{~min}$, centrifuged, then subjected to discontinuous sodium dodecyl sulfate-polyacrylamide gel electrophoresis (SDS-PAGE) (8\% stacking gel with a $12 \%$ resolving gel) and transferred onto polyvinylidine difluoride membranes $(0.45 \mu \mathrm{m})$ (Millipore, Bedford, USA) at $150 \mathrm{~mA}$ for $210 \mathrm{~min}$ in transfer buffer (20 mM Tris, $150 \mathrm{mM}$ glycine, $20 \%$ methanol). Membranes were treated with blocking buffer (10\% nonfat dry milk in TBS: $10 \mathrm{mM}$ Tris- $\mathrm{HCl}, 154 \mathrm{mM} \mathrm{NaCl}, 0.05 \%$ Tween-20, $\mathrm{pH}$ 7.4) for $1 \mathrm{~h}$ at room temperature, and immunolabeled with either anticytochrome $c(1: 10,000)$, anti-PARP $(1: 5,000)$, anti-cytochrome oxidase subunit $(1: 5,000)$ or anti-actin $(1: 10,000)$ primary antibodies for $1 \mathrm{~h}$ at room temperature in TBS/0.1\% Tween-20 on a shaker. After washing the blots three times for $10 \mathrm{~min}$ in TBS/ $/ 0.1 \%$ Tween-20, they were incubated for another hour with horseradish peroxidase-conjugated secondary antibodies (Amersham Pharmacia Biotech, Uppsala, Sweden) at an appropriate dilution. The immunoblotting was detected using an enhanced chemiluminescence kit (Amersham Pharmacia Biotech), according to the manufacturer's instructions.

Caspase activity assay Caspase enzymatic activity in abrintreated HeLa cells was determined by monitoring the cleavage of site-selected synthetic tetrapeptide chromogenic reporter substrates with specificity for Ac-LEHD-AMC (caspase-9-like) or AcDEVD-AMC (caspase-3-like) by using the CaspASE ${ }^{\mathrm{TM}}$ assay system. Cells were lysed at $4^{\circ} \mathrm{C}$ in lysis buffer $(50 \mathrm{mM}$ Hepes$\mathrm{KOH}, \mathrm{pH} 7.4,1 \mathrm{mM}$ EDTA buffer containing $75 \mathrm{mM} \mathrm{NaCl}, 0.1 \%$ Triton X-100, $1 \mathrm{mM}$ dithiothreitol, $1 \mathrm{mM}$ phenylmethylsulfonyl fluoride, $10 \mu \mathrm{g} / \mathrm{ml}$ pepstatin $\mathrm{A}$, and $100 \mathrm{KIU} / \mathrm{ml}$ aprotinin), and spun at $10,000 \times g$ for $20 \mathrm{~min}$ at $4^{\circ} \mathrm{C}$, and the supernatant was removed. Enzymatic reactions $(250 \mu \mathrm{l})$ containing $50 \mu \mathrm{g}$ of cell lysates, and $100 \mu \mathrm{M}$ of chromogenic substrate in reaction buffer $(50$ $\mathrm{mM}$ Hepes-KOH, pH 7.4, buffer containing $75 \mathrm{mM} \mathrm{NaCl}, 2 \mathrm{mM}$ dithiothreitol, $10 \%$ sucrose, and 1\% Chaps) were then performed. The caspase catalyzed release of AMC was monitored under constant agitation by a fluorescence spectrophotometry using excitation at $380 \mathrm{~nm}$ and emission at $440 \mathrm{~nm}$, following $30 \mathrm{~min}$ incubation at $37^{\circ} \mathrm{C}$.

\section{Results}

Abrin induced apoptotic cell death in HeLa cell line The protein biosynthesis inhibitor abrin was tested for its apoptosis-inducing capacity on epithelial HeLa cells. Exposure of HeLa cell cultures to abrin resulted in apoptotic cell death as detected by morphological as well as biochemical criteria (Fig. 1-6).

The major biochemical hallmark of apoptotic cell death is the cleavage of chromosomal DNA at inter-nucleosomal sites into fragments or multiples of about $200 \mathrm{bp}$. The chromosomal DNA of HeLa cells treated with $120 \mathrm{ng} / \mathrm{ml}$ of abrin was fragmented extensively into oligonucleosomes, which were clearly visible as a characteristic DNA ladder pattern of apoptosis following DNA electrophoresis soon after $8 \mathrm{~h}$ of treatment and continued to $36 \mathrm{~h}$ post-treatment, whereas treatment with abrin for $2 \mathrm{~h}$ showed no effect (Fig. 1). HeLa cells treated with $1.5 \mu \mathrm{M}$ staurosporin for $10 \mathrm{~h}$ to induce apoptosis (as positive control) exhibited similar kinetics of chromosomal fragmentation as the abrin-treated cells (Fig. 1, lane 8).

The PI binding capacity was used to further assess abrintreated HeLa cells as a means of quantifying the cell population. Cells showing reduced fluorescence after PI staining compared to those in the $G_{1}$ or $G_{2}$ phase of the cell cycle are depicted to the left of the diagram. This so-called hypodiploid part of the population is composed of apoptotic cells containing degraded DNA, and incorporates less PI than cells with intact DNA. A dose-dependent increase in the hypodiploid population was observed after treatment with 40 , 120 or $200 \mathrm{ng} / \mathrm{ml}$ of abrin (Fig. 2B-2D) compared with the untreated control (Fig. 2A). This dose-dependence was not linear (18.2, 35.7 and $65.1 \%$ apoptotic cells, respectively) as 


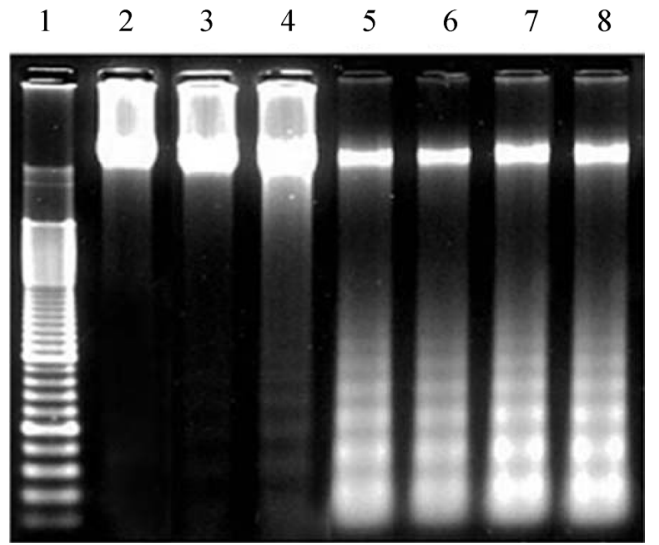

Fig. 1. Fragmentation of cellular DNA into oligonucleosomes in abrin-treated HeLa cells. HeLa cells were treated with $120 \mathrm{ng} / \mathrm{ml}$ of abrin for $2 \mathrm{~h}, 8 \mathrm{~h}, 15 \mathrm{~h}, 24 \mathrm{~h}$, or $36 \mathrm{~h}$ (lanes 3-7) or with 1.5 $\mu \mathrm{M}$ staurosporin for $10 \mathrm{~h}$ (lane 8) (serving as a positive control), or left untreated (lane 2). Lane 1 represents DNA molecular weight markers. DNAs from $2 \times 10^{5}$ cells were extracted and 10 $\mu \mathrm{g}$ DNA were separated on a $1.5 \%$ agarose gel and visualized by ethidium bromide staining under ultra-violet light.

shown in Fig. 2B-2D, indicating that a certain threshold per cell must be exceeded before cells undergo apoptosis. A timecourse experiment using $120 \mathrm{ng} / \mathrm{ml}$ abrin indicated a loss of DNA content by cells after $8 \mathrm{~h}$ of abrin stimulation (data not shown).

Apoptotic cells could also clearly be identified by dramatic
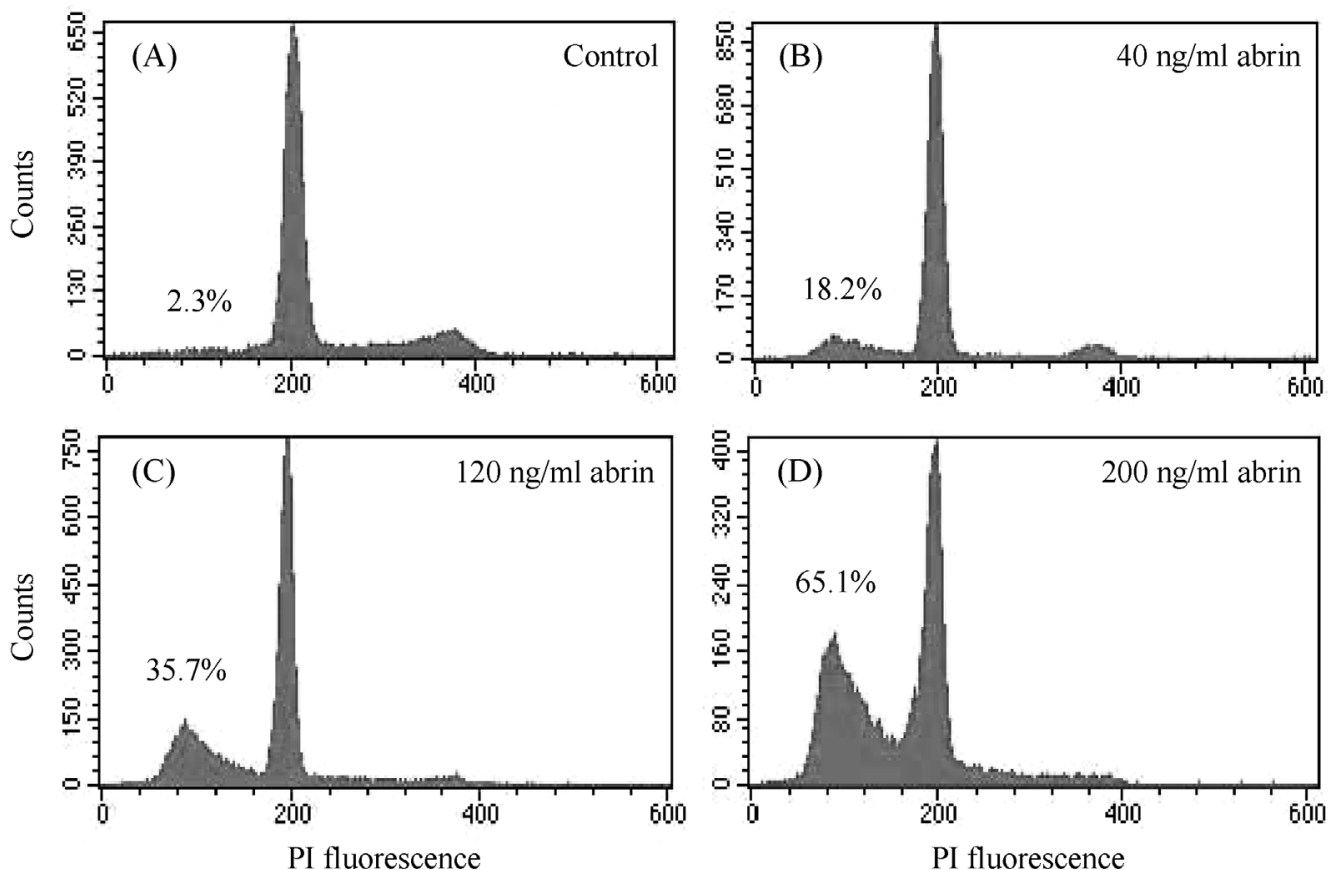

Fig. 2. Flow cytometry analysis of the DNA content of abrin-treated HeLa cells. HeLa cells were incubated with the indicated amounts $(40,120,200 \mathrm{ng} / \mathrm{ml})$ of abrin for $15 \mathrm{~h}(\mathrm{~B}-\mathrm{D})$ or pre-treated with zVAD-fmk $(100 \mu \mathrm{M})$ before $120 \mathrm{ng} / \mathrm{ml}$ abrin treatment or left untreated (A), then harvested, fixed and stained with PI. Cells samples were analyzed by flow cytometry and PI fluorescence intensities were plotted against cell counts. The percentage of cells in the hypodiploid population is shown in the diagrams.

changes in morphology under the light microscope. The morphology of abrin-treated HeLa cells exhibited typical apoptotic features, such as, cell shrinkage, rounding up, and detachment from the culture plate (Fig. 3B), in addition to nuclear breakdown and chromatin condensation (shown by arrows in Fig. 4B), which were determined by staining nuclei with Hoechst 33342.

To detect the yield of DNA strand breaks, which are intimately associated with an apoptotic response, the TUNEL assay was performed after treating HeLa cells with abrin. The results obtained demonstrated that the typical DNA strand breaks observed in apoptotic HeLa cells resulted from abrin treatment, and they were not detected in the untreated control cells (Fig. 5).

Loss of plasma membrane asymmetry before loss of membrane integrity was investigated by simultaneously staining cells with Annexin V and PI to discriminate apoptotic from the necrotic cells. After $8 \mathrm{~h}$ of treatment with $120 \mathrm{ng} / \mathrm{ml}$ abrin, the majority of HeLa cells bound Annexin V, and the majority of Annexin V-stained cells retained plasma membrane integrity, i.e., remaining impermeable to PI, and thus demonstrating an apoptotic mode of cell death (Fig. 6). Notably, the Annexin V/ PI assay permits kinetic measurements of apoptotic cells in relation to the time course after signal induction. Fig. 6 indicates the kinetics of the apoptotic process over elapsed time in abrintreated HeLa cells. Cells treated with $120 \mathrm{ng} / \mathrm{ml}$ of abrin exhibited an early phase apoptotic pattern, PS externalization, as detected by Annexin V binding at 8-36 h after insult (Fig. 6A), followed by membrane disruption, leading to PI uptake starting 

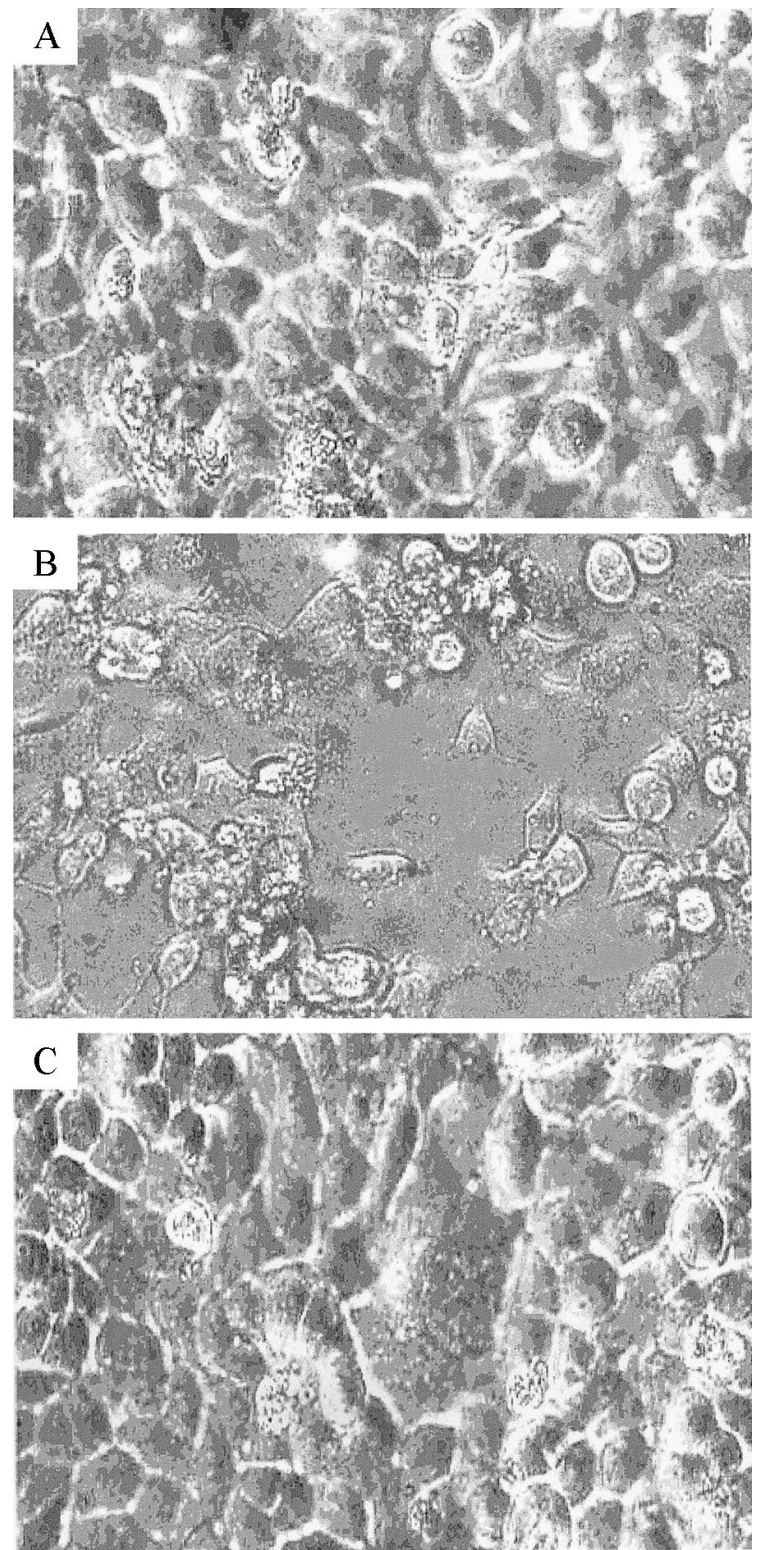

Fig. 3. Morphological changes of abrin-treated HeLa cells. HeLa cells were seeded onto chamber slides, treated with $120 \mathrm{ng} / \mathrm{ml}$ of abrin for $15 \mathrm{~h}$ (B) or pre-treated with $100 \mu \mathrm{M}$ zVAD-fmk followed by $120 \mathrm{ng} / \mathrm{ml}$ abrin (C) or left untreated (A), and then observed under a light microscope.

at $40 \mathrm{~h}$ (Fig. 6B).

Taken together, these data demonstrate that abrin triggered apoptosis in HeLa cells, which is consistent with the findings of previous studies (Hughes et al., 1996).

Cytochrome $c$ was released from mitochondria into cytosol after abrin treatment Much evidence now suggests that cytochrome $c$ plays a central role as an initiator of death machinery in cases of general cellular damage (i.e., radiation, heat shock, cytotoxic agents), or as an amplifier of death signals in cases where caspase activation is initiated by a membrane
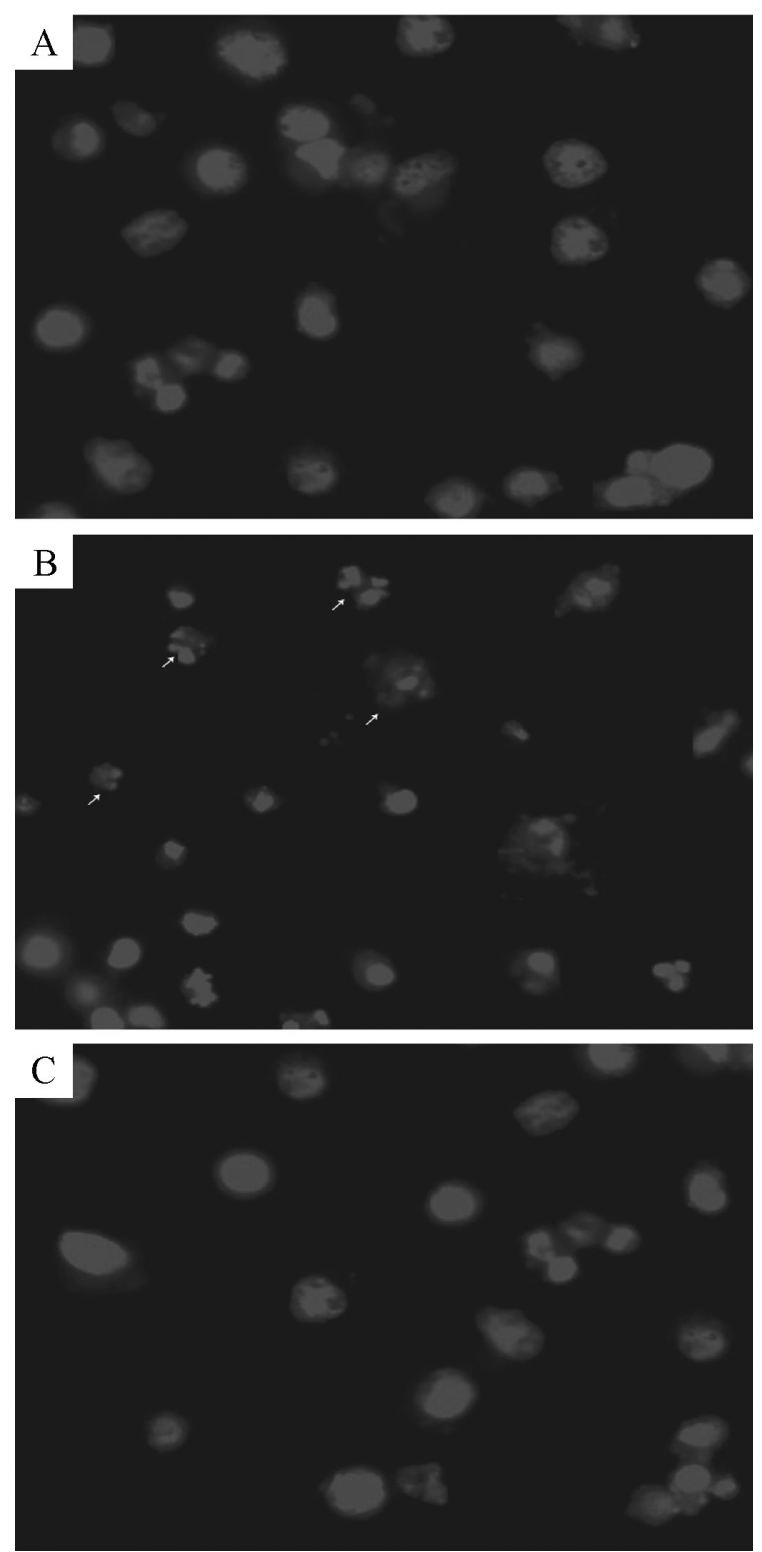

Fig. 4. Nuclear changes of abrin-treated HeLa cells. HeLa cells seeded on chamber slides were treated with $120 \mathrm{ng} / \mathrm{ml}$ of abrin for $15 \mathrm{~h}$ (B) or left untreated (A), and fixed and stained with the DNA binding dye Hoechst 33342. Another cell population was treated with $100 \mu \mathrm{M} z V A D-f m k$ (C) for 30 min prior to abrin treatment. In panel $\mathrm{B}$, the arrows represent the nuclear breakdown and chromatin condensation of HeLa cells induced by abrin.

receptor (Green et al., 1998). To assess whether abrin causes apoptosis by inducing the translocation of cytochrome $c$ from the mitochondrial intermembrane space into the cytosol, the amounts of cytochrome $c$ in the mitochondrial and cytosolic fractions were measured by protein immunoblot analysis at various times after abrin treatment. Cytochrome $c$ release into the cytosolic fraction of HeLa cells was detected as early as $8 \mathrm{~h}$ after abrin treatment and then continued to increase (Fig. 7B), and this was accompanied by a corresponding depletion of 

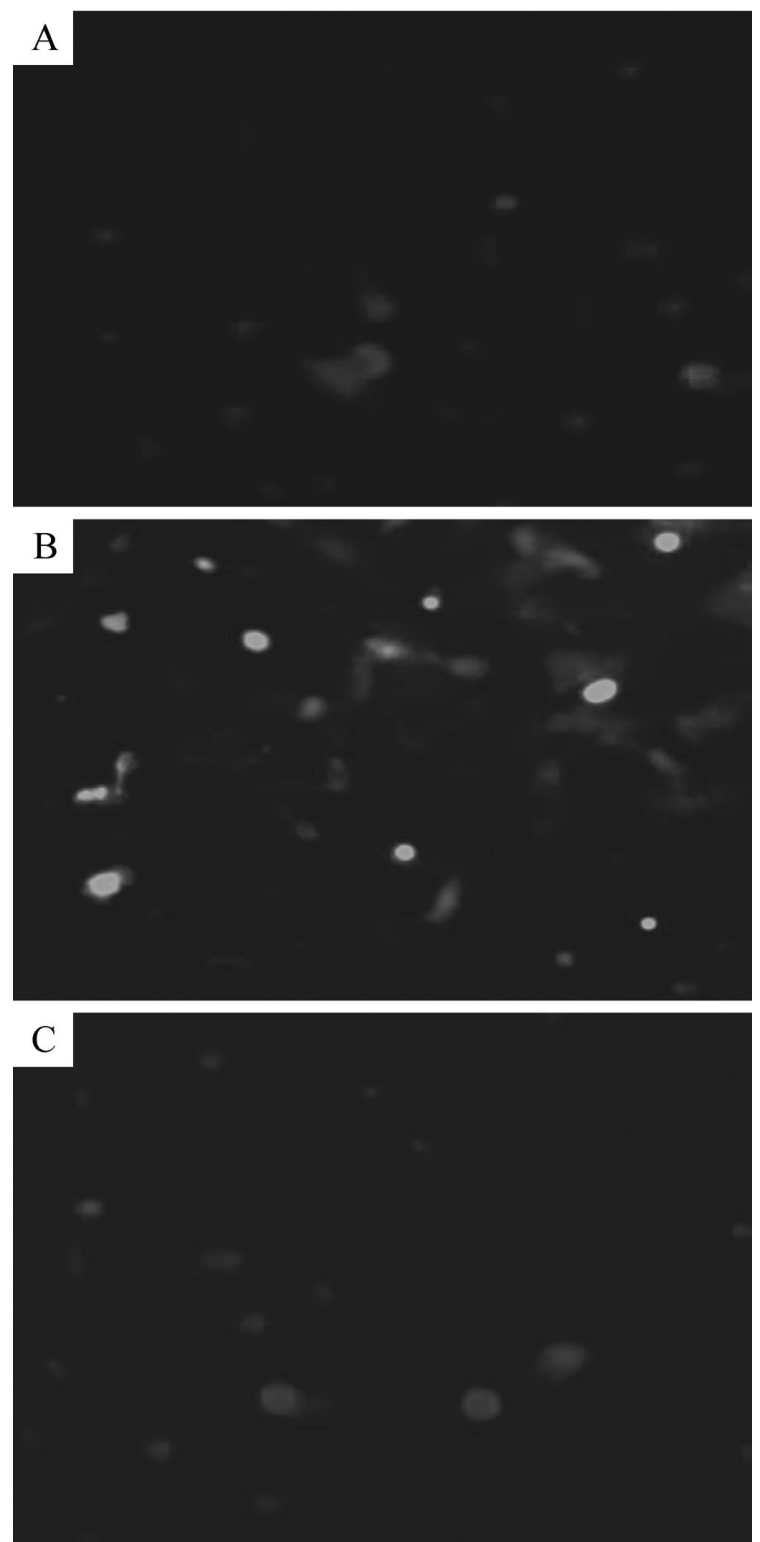

Fig. 5. TUNEL assay of abrin-treated HeLa cells. HeLa cells treated with $120 \mathrm{ng} / \mathrm{ml}$ of abrin for $15 \mathrm{~h}$ (B) and apoptosis was detected by TUNEL assay. A control of untreated cells (A) and a population pretreated with $100 \mu \mathrm{M}$ zVAD-fmk (C) are also presented.

cytochrome $c$ in the mitochondrial fraction (Fig. 7A). These results suggest that abrin induced mitochondrial cytochrome $c$ release into the cytosol.

Abrin induced the activation of caspases The caspases, a family of cysteine proteases, have been demonstrated to act as central executioners of the apoptotic pathway (Hengartner, 2000). To study the involvement of caspases in abrin-induced HeLa cell apoptosis, caspase activation in the cellular extracts was evaluated by monitoring the cleavage of synthetic and natural caspase substrates of caspases. After treating HeLa cells with $120 \mathrm{ng} / \mathrm{ml}$ of abrin for various times, the resulting
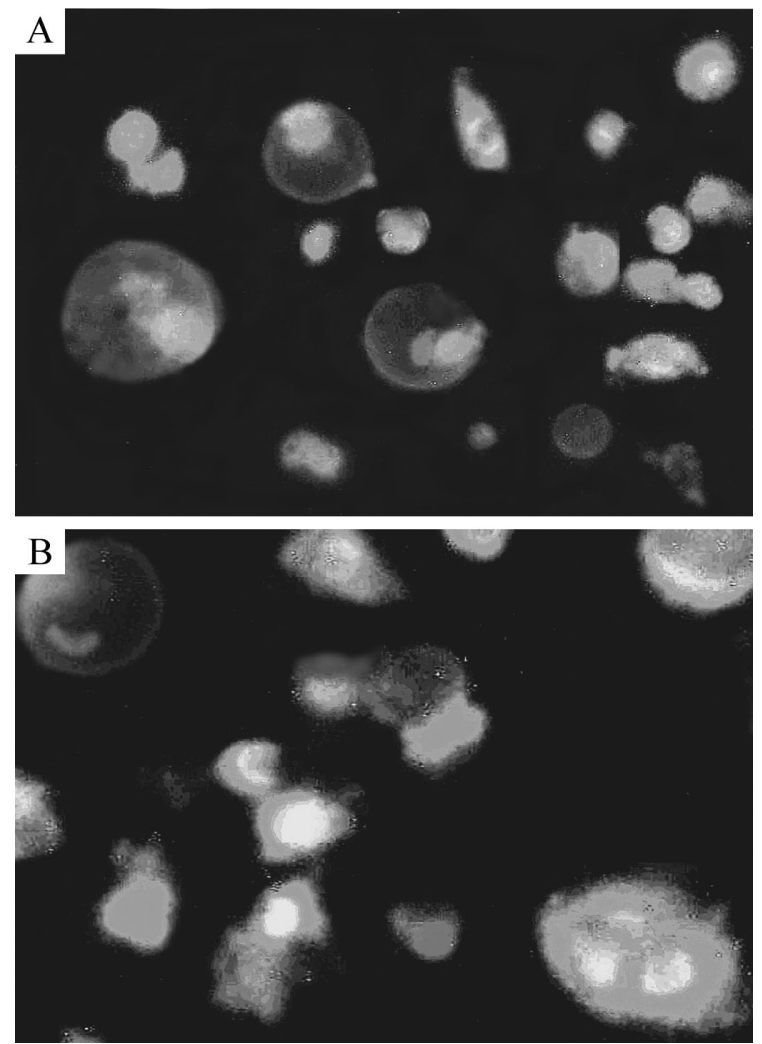

Fig. 6. Annexin V-FLUOS/PI assay for the determination of apoptosis in abrin-treated HeLa cells. HeLa cells seeded on chamber slides were treated with $120 \mathrm{ng} / \mathrm{ml}$ abrin for $8 \mathrm{~h}$ (A) or $40 \mathrm{~h}$ (B), and incubated with Annexin V-FLUOS/PI, and then analyzed under a fluorescence microscope.

time-dependent induction of apoptosis was accompanied by similar time-dependent activations of caspase- 9 and caspase3 , as was indicated by the cleavage of the specific synthetic fluorogenic substrates, Ac-LEHD-AMC (Fig. 8A) or AcDEVD-AMC (Fig. 8B), and of the natural substrate PARP (Fig. 8C). Caspase-9 activation was first detected $8 \mathrm{~h}$ after treatment and was increased more than 4-fold $36 \mathrm{~h}$ after exposure to abrin, as was caspase-3. Moreover, caspase activation was nearly completely inhibited by the cellpermeable irreversible caspase inhibitor, zVAD-fmk (100 $\mu \mathrm{M})$. In addition, the activation of caspase- 3 was indicated by the cleavage of PARP, a commonly used measure of caspase3-like enzymic activity, which further confirmed the activation of caspase-3 during HeLa cell apoptosis by abrin. The intact PARP (116 kDa) was cleaved by a caspase-3-like enzymatic activity to an $85 \mathrm{kDa}$ signature fragment (Fig. 8C).

zVAD-fmk blocked abrin-induced caspases activation but only partially abolished apoptosis We investigated whether the broad-spectrum caspase inhibitor zVAD-fmk interferes with the apoptotic events induced by abrin. Pretreatment of HeLa cells with $100 \mu \mathrm{M}$ zVAD-fmk partially abolished the typical apoptotic phenotype seen upon 
(A)

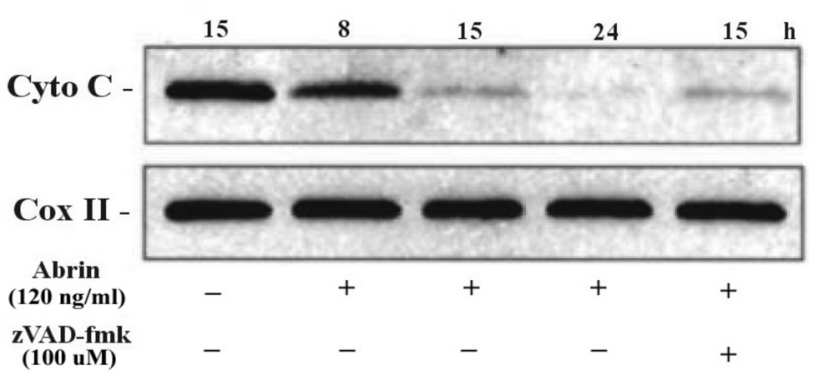

(B)
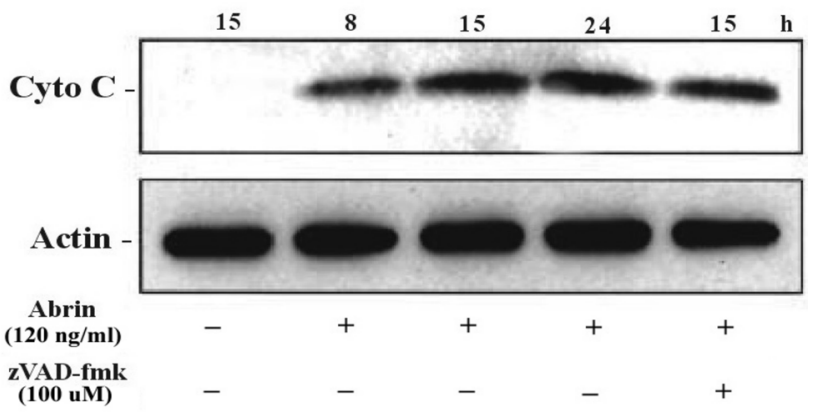

Fig. 7. Release of cytochrome $c$ from mitochondria into the cytosol in abrin-treated HeLa cells. (A) Immunoblot analysis of cytochrome $c$ in mitochondrial fractions. Samples $(25 \mu \mathrm{g})$ of mitochondria isolated from HeLa cells treated with $120 \mathrm{ng} / \mathrm{ml}$ abrin for the indicated time periods $(8 \mathrm{~h}, 15 \mathrm{~h}, 24 \mathrm{~h})$ or in the presence of $100 \mu \mathrm{M}$ zVAD-fmk were subjected to $12 \%$ SDSPAGE and transferred onto polyvinylidene difluoride membranes. The membranes were then probed with antibodies against cytochrome $c$ or the mitochondrial marker cytochrome oxidase subunit II (Cox II), which served as a protein loading control, and the antigen-antibody complex was visualized by enhanced chemiluminescence. (B) Immunoblot analysis of cytochrome $c$ in cytosolic fractions. Samples $(25 \mu \mathrm{g})$ of cytosol from each time point shown in (A) were used for the immunoblot analysis of cytochrome $c$, as described above. The filters were also probed with antibodies against actin, which served as a protein loading control.

incubation with abrin (Figs. 2E, 3C, 4C, 5C), and fragmented nuclei, condensed chromatin, DNA fragmentation, a positive TUNEL result, which were characteristic of abrin-treated HeLa cells, were also prevented partially. The activation of caspases, as indicated by the cleavage of the synthetic substrates and PARP, was almost completely blocked by certain caspase inhibitors (Fig. 8). In summary, these data suggest that the caspases are involved in abrin-triggered apoptosis. Yet there might exist some other aspects of the molecular mechanism of abrin-induced HeLa apoptosis. It is worth noting that the presence of zVAD-fmk did not prevent cytochrome $c$ release from mitochondria (Fig. 7), which is consistent with a recent observation that cytochrome $c$ release is an upstream event in the pathway leading to caspases activation and apoptosis (Bossy et al., 1998).
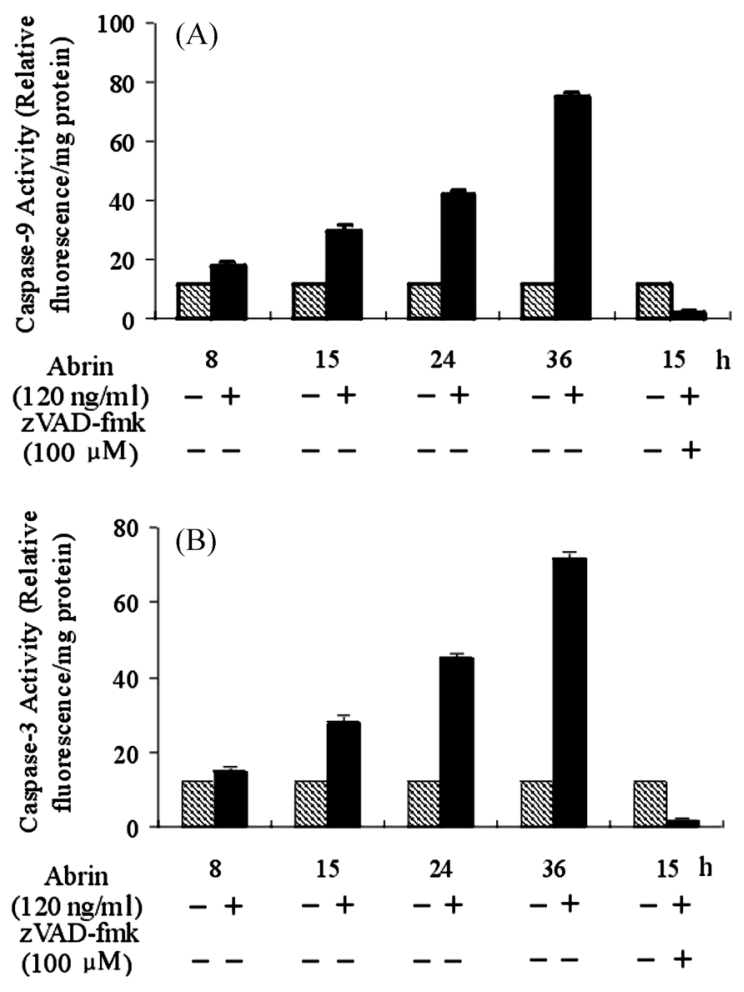

(C)

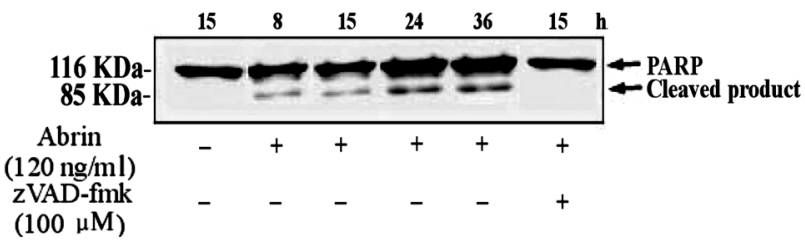

Fig. 8. Abrin induced the activation of caspases in HeLa cells. HeLa cells were incubated for the indicated times with abrin $(120 \mathrm{ng} / \mathrm{ml})$ or with abrin and $100 \mu \mathrm{M}$ zVAD-fmk. The cell lysates were prepared and then analyzed enzymatically for the activation of caspase-9 (A), caspase-3 (B), and for the cleavage of PARP (C), as described in "Materials and Methods". The results of A and B are representative of three separate experiments. The data shown are means \pm S.D. of three experiments.

\section{Discussion}

Apoptosis is a highly conserved phenomenon that plays an important role in the regulation of the cellular activities of eukaryotes. A wide variety of stimuli can induce a cell to undergo a rapid, inflammatory-free clearance (Green et al., 1998). Reports have demonstrated that some toxins (e.g. ricin) are apoptosis inducers that trigger a sequence of events ultimately causing apoptosis (Hughes et al., 1996; Komatsu et al., 1998; Oda et al., 1998). In the present study, the toxin abrin, a type-ribosome inactivating protein, was identified to induce apoptotic cell death in HeLa cells, which exhibited the characteristic morphological and biochemical features of apoptosis, including cell shrinkage, internucleosomal DNA fragmentation, chromatin condensation and nuclear 
fragmentation, DNA single strand breaks, PS externalization, mitochondrial cytochrome $c$ release, and caspases activation.

Mitochondria fulfill a pivotal role in the control of cell's life and death. At least three general mechanisms are known whereby mitochondria trigger apoptotic or nonapoptotic cell death, these include; (i) the disruption of electron transport, oxidative phosphorylation, and ATP production; (ii) the release of resident mitochondrial proteins, such as cytochrome $c$ and apoptosis-inducing factor that trigger the activation of caspase family proteases; and (iii) the alteration of the cellular reduction-oxidation potential (Green et al., 1998). These biochemical perturbations resulting from alterations in mitochondrial functions have been proposed to be the essential events that commit a cell to undergo apoptosis. The translocation of holocytochrome $c$ from mitochondria into the cytosol during apoptosis, which is observed during apoptosis processes induced by various signals, inactivates the electron transfer chain and triggers caspases activation through Apaf-1 (Reed, 1997). Cytochrome $c$-triggered caspases play a critical role in the execution phase of apoptosis. Moreover, caspasemediated cleavages of specific substrates explains several of the characteristic biochemical and morphological changes associated with apoptosis (Hengartner, 2000).

This study demonstrates cytochrome $c$ release from mitochondria into the cytosol and the subsequent sequential activations of caspase- 9 and caspase- 3 during the process of abrin-induced apoptotic cell death in HeLa cells. These data suggest that the mitochondrial pathway is involved in abrininduced apoptosis, whereby alterations in mitochondrial function provoke the translocation of cytochrome $c$ from mitochondria to the cytosol. This cytochrome $c$ release then initiates a cascade that leads to the activation of caspase- 3 through caspase-9 and Apaf-1 association.

Further work may clarify whether additional upstream events exist, and which signal factors trigger the mitochondrial cytochrome $c$ release. It is compelling that the most recent literature on the signal transduction mechanism of abrin-induced apoptosis reported that the interaction of abrin with AOP-1, a thiol-specific antioxidant protein, can shield sulfhydryl groups, and that this results in the inhibition of antioxidant activity and an increase in the intracellular levels of reactive oxygen species (Shih et al., 2001). The reactive oxygen species, which act as signaling intermediates and are involved in the signal transduction pathway of apoptosis, then mediate abrin-induced apoptosis.

It is worth noting that zVAD-fmk, a broad-spectrum caspase inhibitor, was unable to completely prevent the apoptosis caused by abrin. A possible explanation for this phenomena is that the activation of caspase is not the only pathway involved in abrin-induced apoptosis. As abrin belongs to the type-ribosome inactivating protein family, which contain a toxophoric A-chain with protein synthesis inhibitory activity, we speculate that the stress caused by the inhibition of protein synthesis partially contributes to abrintriggered apoptosis.
Based on our results and the findings of others, we propose the following model for the induction of apoptosis by abrin. Abrin-induced apoptotic cell death in HeLa cells involves at least two pathways. The first involves the inhibition of protein synthesis due to its $\mathrm{N}$-glycosidase activity, and the other the alteration of mitochondrial function due to an increase in reactive oxygen species or some other unknown factor, which induces the translocation of mitochondrial cytochrome $c$ to the cytosol. Cytosolic cytochrome $c$ facilitates the activation of caspase-3 and of other effector caspases by caspase- 9 oligomerization with the adapter molecule Apaf-1 in the presence of dATP/ATP.

Acknowledgments This research work was supported by the Natural Science Foundation of Hubei Province (4006016031), P. R. China.

\section{References}

Baluna, R., Rizo, J., Gordon, B. E., Ghtie, V. and Vitetta, E. S. (1999) Evidence for a structural motif in toxins and interleukin-2 that may be responsible for binding to endothelial cells and initiating vascular leak synetrome. Proc. Natl. Acad. Sci. USA 96, 3957-3962.

Bossy, W. E., Newmeyer, D. D. and Green, D. R. (1998) Mitochondrial cytochrome $c$ release in apoptosis occurs upstream of DEVD-specific caspase activation and independently of mitochondrial transmembrane depolarization. EMBO J. 17, 37-49.

Cryns, V. and Yuan, J. (1998) Proteases to die for. Genes Dev. 12, 1551-1570.

Endo, Y., Mitsui, K. and Motizuki, K. (1987) The mechanism of action of ricin and related toxic lectins on eukaryotic ribosomes. J. Biol. Chem. 262, 5908-5912.

Green, D. R. (1998) Apoptotic pathways: the roads to ruin. Cell. 94, 695-698.

Green, D. R. and Reed, J. C. (1998) Mitochondria and apoptosis. Science. 281, 1309-1312.

Hengartner, M. O. (2000) The biochemistry of apoptosis. Nature. 407, 770-776.

Hughes, J. N., Lindsay, C. D. and Griffiths, G. D. (1996) Morphology of ricin and abrin exposed endothelial cells is consistent with apoptotic cell death. Hum. Exp. Toxicol. 15, 443-451.

Jacobson, M. D., Weil, M. and Raff, M. C. (1997) Programmed cell death in animal development. Cell. 88, 347-354.

Komatsu, N., Oda, T. and Muramatsu, T. (1998) Involvement of both caspase-like proteases and serine proteases in apoptotic cell death induced by ricin, modeccin, diphtheria toxin and pseudomonas toxin. J. Biochem. 124, 1038-1044.

Li, P., Nijhawan, D., Budihardjo, I., Srinivasula, S. M., Ahmad, M., Alnemri, E. S. and Wang, X. (1997) Cytochrome $c$ and dATP-dependent formation of Apaf-1/caspase-9 complex initiates an apoptotic protease cascade. Cell 91, 479-489.

Liu, C. L., Tsai, C. C., Lin, S. C., Wang, L. I., Hsu, C. I., Hwang, M. J. and Lin, J. Y. (2000) Primary structure and function analysis of the Abrus precatorius agglutinin A chain by site- 
directed mutagenesis. Pro (199) of amphiphilic alpha-helix H impairs protein synthesis inhibitory activity. J. Biol. Chem. 275, 1897-1901.

Muzio, M., Salvesen, G. S. and Dixit, V. M. (1997) FLICE induced apoptosis in a cell-free system. J. Biol. Chem. 272, 2952-2956.

Oda, T., Komatsu, N. and Muramatsu, T. (1998) Diisopropylfluorophosphate (DFP) inhibits ricin-induced apoptosis of MDCK cells. Biosci. Biotechnol. Biochem. 62, 325-333.

Reed, J. C. (1997) Cytochrome $c$ : can't live with it- can't live without it. Cell 91, 559-562.
Shih, S. F., Wu, Y. H., Hung, C. H., Yang, H. Y. and Lin, J. Y. (2001) Abrin triggers cell death by inactivating a thiol-specific antioxidant protein. J. Biol. Chem. 276, 21870-21877.

Wu, A. M., Wu, J. M., Her, P. A., Chow, L. P. and Lin, J. Y. (2001) Carbohydrate specificity of a toxic lectin, abrin A, from the seeds of Abrus precatorius (jequirity bean). Life Sci. 69, 2027-2038.

Wu, T. H., Chow, L. P. and Lin, J. Y. (1998) Sechiumin, a ribosome-inactivating protein from the edible gourd, Sechium edule Swartz purification, characterization, molecular cloning and expression. Eur. J. Biochem. 255, 400-408. 